\title{
A simplified planar model for geosynthetics reinforced composite foundation subjected to vertical load
}

\author{
Weiming Huang ${ }^{1, *}$, Chao Ren ${ }^{2}$, Jinchang Wang ${ }^{3}$, and Qinyun $\mathrm{Yu}^{4}$ \\ ${ }^{1}$ College of Architecture and Civil Engineering, Wenzhou University, Wenzhou 325035, PR China. \\ ${ }^{2}$ Zhejiang Highway\&water Transportation Engineering Consulting Limited Liability Company, Hangzhou 310006, PR China. \\ ${ }^{3}$ Institute of Transportation Engineering, Zhejiang University, Hangzhou 310058, PR China. \\ ${ }^{4}$ Hangzhou Luda Highway Engineering Corporation, Hangzhou 310004, PR China
}

\begin{abstract}
A simplified planar model for geosynthetics reinforced composite foundation under large-scale loading was established with a new consolidation analysis. The cushion was modeled by modified Pasternak model and the reaction of pile and subsoil was modeled by Winkler model. The effect of geosynthetics layer was directly considered as an elastic cable and the subsoil was divided into numerous columns with only vertical drainage. The solution was obtained by a finite difference based iterative scheme. The feasibility of the model was demonstrated by a case study. Then a parameter study was executed to analyze the effect of several influential factors. The results showed that there is a critical pile -to-pitch ratio that makes the increase of the stiffness of the geosynthetic material the most conducive to deformation control.
\end{abstract}

\section{Introduction}

For decades, as an efficient and economic method for improving foundations, the geosynthetics reinforced composite foundations have been widely used and have attracted widespread attention. This type of reinforced system basically consists of two components:1) reinforced subsoil with vertical reinforcement such as a group of pile-liked inclusions 2) reinforced cushion with horizontal reinforcement composed of a granular fill layer embedding one or several geosynthetics layers. The present design guidelines for this composite foundation ${ }^{[1,2,3]}$ are usually based on a full-developed certain arching model to determine the load distribution on geosynthetics layer whereas catenary curve or other curves are assumed to describe the geosynthetics layer deformation. It results in a coarse consideration of the deformation-related load transmission mechanism between the cushion and subsoil and it is more prevail for the embankment construction, of which the vertical load is mainly transmitted to the pile-like inclusions through a fully developed arching effect. However, the application of geosynthetic reinforced foundation has been extended to workshop foundation improvement, airport foundation improvement and so on, where the height of the granular fill may be less enough to form a full soil arching.

With respect to the only geosynthetics reinforced foundation, Madhav and Poorooshasb et al. ${ }^{[4,5,6,7]}$ proposed a planar-strain model to analyze the effect of the properties of cushion, subsoil and geosynthetics layer on the reinforced system. The cushion and the subsoil were represented by Pasternak model and Winkler model respectively and the behavior of the interface between the geosynthetics layer and the subsoil or cushion was modeled by frictional mechanism. Furthermore, Deb et al. ${ }^{[8]}$ considered the effect of the subsoil consolidation by incorporating an average degree of consolidation of the subsoil when analyzing the composite foundation improved by stone column and geosynthetics. However, the determination of the interfacial frictional coefficients is quite difficult and the frictional mechanism cannot reflect the deformation-related load transmission and the effect of geosynthetics stiffness. In order to take the stiffness of the geosynthetics into account, Yin et al. ${ }^{[9]}$ related the interfacial stress to the horizontal shear response of the cushion for an only geosynthetics reinforced foundation. In summary, the deformation-related load transmission mechanism is not systematically considered in the present design guidelines or simplified analysis methods. The previous researches mainly focused on the modelling of embankment composite foundation where the arching is fully developed, and the effect of geosynthetics layer and the consolidation of subsoil is not fully considered in the previous simplified modelling. Based on the predecessor's researches ${ }^{[7-9]}$, by similar

*Corresponding author: 20200206@wzu.edu.cn 
proper simplifications and introducing a new consolidation analysis to consider the influence of the uneven distribution load at the top of the subsoil, this paper proposed a new model to analyze the interaction of each system components under large-scale loading condition with only vertical surcharge load.

\section{Formulation}

For large-scale loading condition, a planar component of the reinforced system can be selected for analysis as shown in Fig. 1, including two half pile walls, a subsoil layer between two adjacent piles, a cushion layer and a geosynthetics layer. The basic assumptions are listed as below:

a) With regard to the large-scale loading condition, a planar strain model is considered.

b) Following Yin et al. [9]'s analysis, the cushion is modeled by a series of stiff shear blocks and their shear behavior is divided into two directional independent ones. The vertical shear of the cushion is represented by a modified Pasternak model with a nonlinear shear-strain curve of Konder ${ }^{[10]}$ 's model. The horizontal shear stress acting on the geosynthetics layer is determined by a compatible deformation assumption for the geosynthetics layer and the bottom of the cushion layer.

c) For simplification, the subsoil is considered as a modified Winkler model with a new consolidation analysis introduced by neglecting the pile-like inclusion's influence on the subsoil consolidation, which is more suitable for pile-like inclusion with low permeability. Only the vertical drainage of the subsoil layer is considered, and the water table is located at the ground. The subsoil layer is divided into numerous columns with only vertical drainage.

d) A single geosynthetics layer is placed at the bottom of the cushion.

e) Since the pile-liked inclusions in this study is far stiffer than the subsoil, the diversity of the settlement in the range of the pile area is neglected. And for simplification, the strain of geosynthetics layer in the pile area is assumed to be uniform.

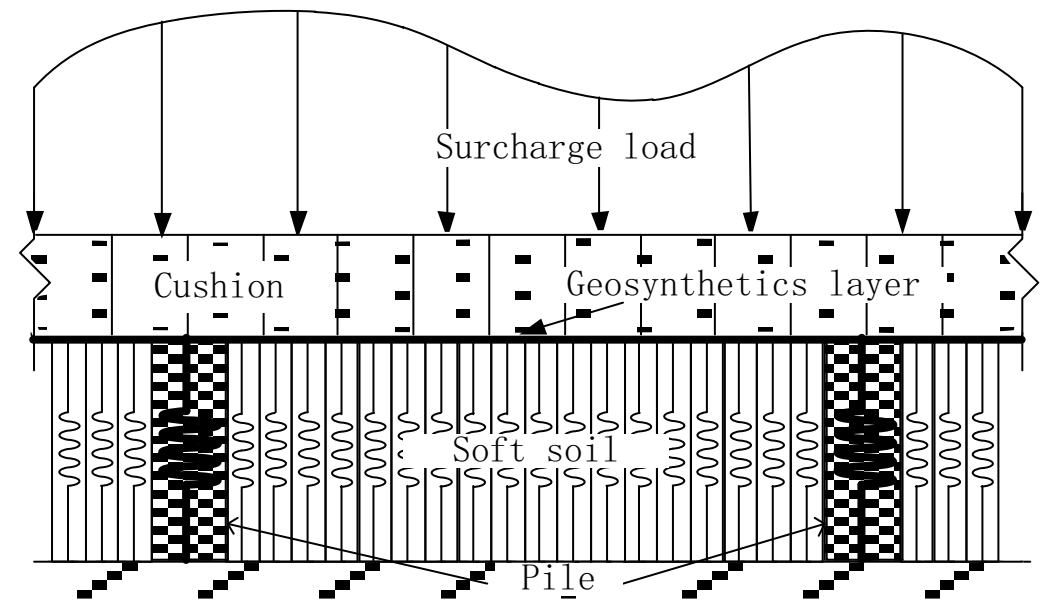

Figure 1 The sketch of the planar model for the reinforced system

According to symmetry, one half of the model can be further selected for analysis and be divided into numerous elements. Based on the above assumptions, the forces acting on a reinforced cushion element can be illustrated in Fig.2. The horizontal and vertical axes are denoted by $\mathrm{x}$ and $\mathrm{y}$, respectively.

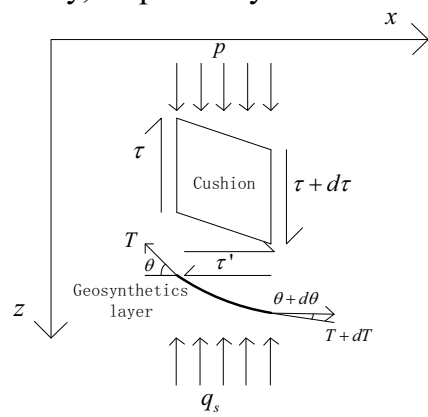

Figure 2 The forces acting on the reinforced cushion element

Considering the vertical equilibrium of the reinforced cushion element and neglecting the second order smalls, one can get

$$
p+\frac{\mathrm{d} \tau}{\mathrm{d} x} h+T \frac{\mathrm{d}^{2} w}{\mathrm{~d} x^{2}}+\frac{\mathrm{d} T}{\mathrm{~d} x} \frac{\mathrm{d} w}{\mathrm{~d} x}-q_{s}=0
$$

where $\tau=$ the side stress of rigid shear block and can be determined by $\tau=G \frac{\mathrm{d} w}{\mathrm{~d} x} ; w=$ the vertical displacement; $G=$ the shear stiffness of cushion; $h=$ the thickness of cushion; $T=$ the tension of geosynthetics layer; $q_{\mathrm{s}}=$ the subsoil reaction pressure; $p=$ the surcharge load.

According to Konder ${ }^{[10]}$ 's model, the shear stiffness of cushion $G$ can be expressed as

$$
G=\frac{g}{1+\frac{g}{\tau_{\max }}\left|\frac{\mathrm{d} w}{\mathrm{~d} x}\right|}
$$

where $g$ is the initial shear stiffness of cushion, and $\tau_{\max }$ is the ultimate shear strength of cushion.

Following Deb et al. ${ }^{[7,8]}$ 's analysis, the reaction pressure of the subsoil can be expressed as

$$
q_{s}=k_{s} w+u_{e}
$$


where $k_{s}=$ the subgrade reaction stiffness and $u_{e}=$ the excess pore pressure. Similarly, according to the horizontal equilibrium of the reinforced cushion element, one has

$$
\frac{\mathrm{d} T}{\mathrm{~d} x}=\tau^{\prime}
$$

where $\tau^{\prime}$ is the interfacial shear force between the cushion layer and geosynthetics layer. To introduce the compatible deformation equation of the geosynthetics layer and reduce the number of coefficient, Yin et al. ${ }^{[9]}$ take the horizontal displacement at the top of the cushion as zero such that the interface shear stress can be defined as

$$
\tau^{\prime}=G \frac{v}{h}
$$

where $v=$ horizontal displacement.

In this paper the geosynthetics layer is considered as an elastic cable. Hence, the tension $T$ can be expressed as

$$
T=E_{g}\left(\frac{\mathrm{d} u}{\mathrm{~d} x}+\frac{1}{2}\left(\frac{\mathrm{d} w}{\mathrm{~d} x}\right)^{2}\right)
$$

Combining Eqs.(5), (6), and (7), it gives

$$
\frac{\mathrm{d}^{2} T}{\mathrm{~d} x^{2}}=-\frac{G}{\tau_{\max }} \frac{\mathrm{d}^{2} w}{\mathrm{~d} x^{2}} \frac{\mathrm{d} T}{\mathrm{~d} x}+\frac{G}{h} \frac{T}{E_{g}}-\frac{G}{2 h}\left(\frac{\mathrm{d} w}{\mathrm{~d} x}\right)^{2}
$$

With regard to the consolidation of subsoil improved by stone column, Deb et al. ${ }^{[8]}$ adopted Hird et al. ${ }^{[11]}$ 's equivalent plane strain consolidation equation. However, the presence of the geosynthetics layer on the load transmission leads to a spatial diversity of load distribution at the surface of the subsoil such that the reaction of subsoil is time and space dependent in fact. With assumption (3), it can be analyzed by dividing the subsoil into several columns with only vertical drainage. Since the cushion is constructed by coarse granular soil, the upside of the column is considered as permeable. And the downside of the column is considered as impermeable. According to Terzaghi's one dimensional consolidation theory, the average excess pore pressure $u_{\mathrm{e}}$ of the column can be obtained by

$$
\begin{gathered}
u_{e}=\sum_{n=1}^{\infty} \frac{8}{(n \pi)^{2}}\left(q_{s 0}+\int_{0}^{t} \frac{d q_{s}}{d t} e^{a \tau} d \tau\right) e^{-a t} \\
a=c_{v}\left(\frac{n \pi}{2 H}\right)^{2}
\end{gathered}
$$

where $q_{\mathrm{s} 0}=$ the initial surcharge load; $C_{v}=$ the consolidation coefficient of subsoil layer; $H=$ the depth of subsoil.

For simplification, Eq.(10) can be used to determined $u_{\mathrm{e}}$.

$$
u_{e}=\frac{8}{\pi^{2}}\left(q_{s 0}+\int_{0}^{t} \frac{d q_{s}}{d t} e^{a \tau} d \tau\right) e^{-a t}
$$

Substituting Eq.(10) into Eq. (3) and executing a differential operation with regard to time produces,

$$
\left(1-\frac{8}{\pi^{2}}\right) \frac{d q_{s}}{\mathrm{~d} t}-k_{s} \frac{d w}{d t}+a\left(q_{s}-k_{s} w\right)=0
$$

As shown in Fig.(3), the load borne by the pile-likes inclusions includes three parts: one is the surcharge applied directly at the pile or pile cap area, one is transmitted from the cushion shearing at the edge of pile or pile cap and another is transmitted by the geosynthetics layer. Considering the vertical equilibrium of the pile or pile cap area, one can get

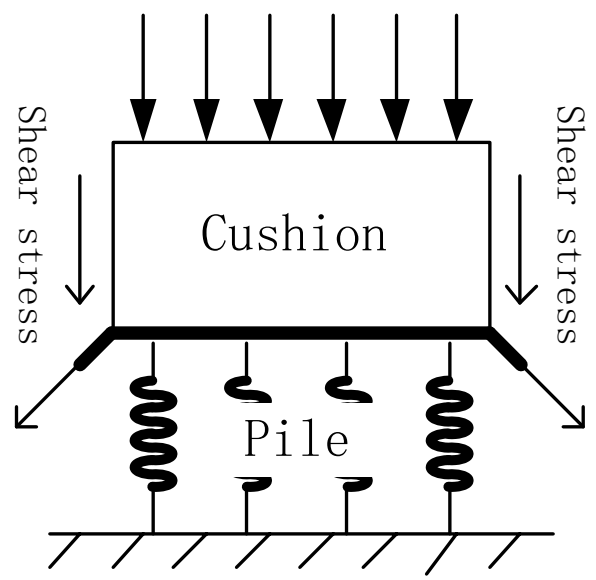

Figure 3 The vertical equilibrium of the pile-like inclusions element

$$
p d_{p}-k_{p} w_{0} d_{p}+G h \frac{d w}{d x_{0}}+T_{0} \frac{d w}{d x_{0}}=0
$$

where the subscript 0 represents that the point is located at the edge of pile-liked inclusion area and $k_{\mathrm{p}}$ is the equivalent pile reaction stiffness coefficient which can be determined by Eq.(13) as suggested by Zhang ${ }^{[12]}$. Herein, $K$ is the pile reaction stiffness coefficient and can be derived from load-settlement curve of the pile.

$$
\begin{gathered}
k_{p}=\frac{K A_{p}+k_{s}\left(A_{r}-A_{p}\right)}{A_{r}} \\
k_{s}=\frac{E_{S}}{H} \quad(14)
\end{gathered}
$$

where $A_{\mathrm{p}}=$ the area of pile, and $A_{\mathrm{r}}=$ the area of equivalent pile wall between two adjacent piles.

According to assumption (5), the average strain at pile-like inclusion area can be estimated as

$$
\varepsilon=\frac{v_{0}}{d_{p}}
$$

Thus, the tension at the edge of pile area can be obtained by

$$
T_{0}=\mathrm{E}_{g} \frac{v_{0}}{d_{p}}
$$

Note that $\frac{\mathrm{d} T_{\mathrm{o}}}{\mathrm{d} x}=G \frac{v_{\mathrm{O}}}{h}$, substituting it into Eq.(16), it gives 


$$
T_{0}=\frac{\mathrm{E}_{g} h}{G d_{p}} \frac{\mathrm{d} T_{0}}{\mathrm{~d} x}
$$

At the center point of the two adjacent piles (where $x=l$ ), the boundary condition at $\mathrm{t}>0$ can be expressed as

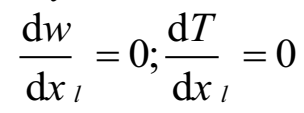

where the subscript $l$ represents that the point is located at the center point of the two adjacent piles. When $t=0$, the load at the area between two adjacent piles is totally borne by the water of the subsoil layer, i.e.,

$$
q_{s}=p ; w=0 ; T=0
$$

\section{Numerical Solution}

To resolve the problem, the finite difference method was adopted to solve the three governing equations Eqs.(1), (7) and (11). Divide the area into $n$ number of elements with $n+1$ number of nodes $(i=1,2,3, \ldots, n+1)$. The mesh size $\Delta x$ is equal to $l / n$. The relevant differentials in the above equations can be expanded as

$$
\begin{aligned}
& \frac{\mathrm{d} w}{\mathrm{~d} x_{i, j}}=\frac{w_{i+1, j}-w_{i-1, j}}{2 \mathrm{~d} x} \\
& {\frac{\mathrm{d}^{2} w}{\mathrm{~d} x^{2}}}_{i, j}=\frac{w_{i+1, j}-2 w_{i, j}+w_{i-1, j}}{\mathrm{~d} x^{2}}
\end{aligned}
$$

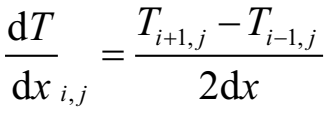

$$
\begin{aligned}
& \frac{\mathrm{d}^{2} T}{\mathrm{~d} x^{2}}{ }_{i, j}=\frac{T_{i+1, j}-T_{i, j}+T_{i-1, j}}{\mathrm{~d} x^{2}} \\
& \frac{\mathrm{d} q_{s}}{\mathrm{~d} t}{ }_{i, j}=\frac{q_{s i, j}-q_{s i, j-1}}{\mathrm{~d} t} \\
& \frac{\mathrm{d} w}{\mathrm{~d} t}{ }_{i, j}=\frac{w_{i, j}-w_{i, j-1}}{\mathrm{~d} t}
\end{aligned}
$$

Herein, the first subscript $i$ refers to the node and the second subscript $j$ denotes the time step. Substituting the above differential schemes into the above governing equations and rearranging them produces,

$$
\left\{\begin{array}{l}
\left(\frac{\left(G^{\prime} h+T\right)_{i, j}}{d x^{2}}-\frac{\left(\frac{d T}{d x}\right)_{i, j}}{2 d x}\right) w_{i-1, j}-\frac{2\left(G^{\prime} h+T\right)_{i, j}}{d x^{2}} w_{i, j}+\left(\frac{\left(G^{\prime} h+T\right)_{i, j}}{d x^{2}}+\frac{\left(\frac{d T}{d x}\right)_{i, j}}{2 d x}\right) w_{i+1, j}-q_{s i, j}=-p_{i, j} \\
\left(\frac{1}{d x^{2}}-\frac{\left(\frac{G}{\tau_{\max }} \frac{d^{2} w}{d x^{2}}\right)_{i, j}}{2 d x}\right) T_{i-1, j}-\left(\frac{2}{d x^{2}}+\frac{G_{i, j}}{h E_{g}}\right) T_{i, j}+\left(\frac{1}{d x^{2}}+\frac{\left(\frac{G}{\tau_{\max }} \frac{d^{2} w}{d x^{2}}\right)_{i, j}}{2 d x}\right) T_{i+1, j}=-\left(\frac{G}{2 h}\left(\frac{d w}{d x}\right)^{2}\right)_{i, j} \\
1-\frac{8}{\pi^{2}} \\
\left(\frac{8}{d t}+a\right) q_{s i, j}-\left(\frac{k_{s}}{d t}+a k_{s}\right) w_{i, j}=\frac{1-\frac{8}{\pi^{2}}}{d t} q_{s i, j-1}-\frac{k_{s}}{d t} w_{i, j-1}
\end{array}\right.
$$

Similarly, the boundary and initial conditions can be expanded as

$$
\begin{gathered}
-\frac{G_{0} h+T_{0}}{2 d x} w_{-1}-k_{p} d_{p} w_{0}+\frac{G_{0} h+T_{0}}{2 d x} w_{1}=-p d_{p} \\
-\frac{E_{g} h}{2 G_{0} d_{p} d x} T_{-1}-T_{0}+\frac{E_{g} h}{2 G_{0} d_{p} d x} T_{1}=0 \\
w_{n+1}=w_{n-1} \quad \text { (22b) } \\
T_{n+1}=T_{n-1} \quad(22 \mathrm{c})
\end{gathered}
$$

Eq.(21) can be rearranged into a matrix form as,

$$
[K(\psi)]\{\psi\}=\{b(\psi)\}
$$

where

$$
\psi_{i, j}=\left[w_{i, j}, T_{i, j}, q_{s i, j}\right]
$$

The numerical solutions are obtained by an iterative procedure with a convergence criterion as

$$
\frac{\left|\psi_{i, j}{ }^{(k+1)}-\psi_{i, j}{ }^{(k)}\right|}{\left|\psi_{i, j}{ }^{(k)}\right|}<=0.0001
$$

\section{Case Study}

To verify the present analytical model, the case from Fei et al.(2009) was used. The embankment is located in the northern outskirt of Shanghai. The embankment consists mainly of granular material. As shown in Fig.4, the construction of embankment is step-wise and with a nearly constant construction rate. The final height of the embankment including a $0.6 \mathrm{~m}$ gravel layer is $5.6 \mathrm{~m}$. Neglecting the arching effect of the fill, a uniform final load of $104 \mathrm{kPa}$ is assumed to be applied on the cushion top. The main parameters used in the calculation are listed in Table 1. The coefficient $K$ in Eq.(15) is derived from the measured data and equal to $40.71 \mathrm{MN} / \mathrm{m}^{3}$. The ultimate shear strength $\tau_{\max }$ is dependent on the characteristics of cushion material. It should be checked by experiment. Herein, an estimation of $100 \mathrm{kPa}$ is used in this case study. 
Table 1 The parameters used in case study

\begin{tabular}{|c|c|c|c|c|c|c|c|}
\hline $\begin{array}{l}\text { permeability } \\
\text { coefficient } \\
\left(10^{-4} \mathrm{~m} / \mathrm{d}\right)\end{array}$ & $\mathrm{k}$ & $\begin{array}{l}\text { Depth of } \\
\text { subsoil } \\
\text { layer } \\
\mathrm{H}(\mathrm{m})\end{array}$ & $\begin{array}{c}\text { Vertical } \\
\text { ultimate } \\
\text { bearing } \\
\text { capacity } \\
(\mathrm{KN})\end{array}$ & $\begin{array}{l}\text { Compressive } \\
\text { module } \\
\text { Es (Mpa) }\end{array}$ & $\begin{array}{l}\text { Geosynthetics } \\
\text { stiffness } \\
\text { Eg }(\mathrm{KN} / \mathrm{m})\end{array}$ & $\begin{array}{l}\text { Initial shear } \\
\text { stiffness for } \\
\text { cushion } \\
\text { G (Mpa) }\end{array}$ & $\begin{array}{l}\text { Poisson's } \\
\text { ratio for } \\
\text { subsoil } \\
v_{s}\end{array}$ \\
\hline 5.40 & & 16 & 1380 & 6.8 & 1180 & 13 & 0.36 \\
\hline
\end{tabular}

Note: $E_{s}$ and $v$ are height-weighted average value and $k$ is derived from Eq.(26).

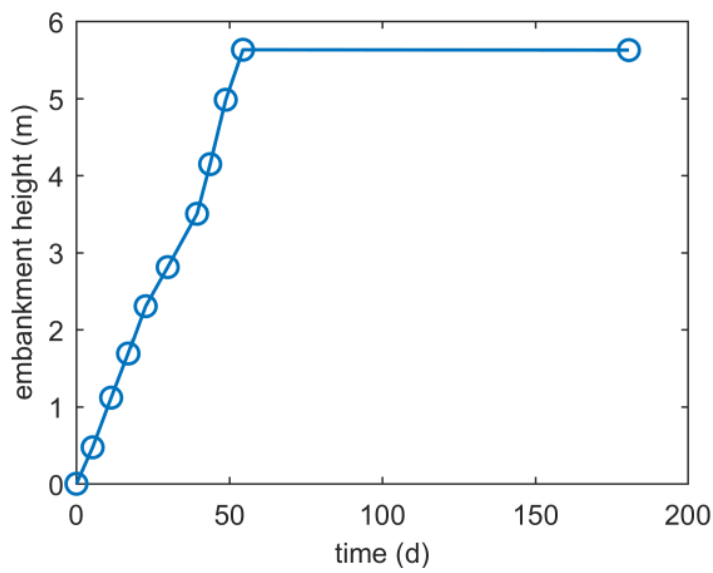

Figure 4 The scheme for embankment construction

$$
k=\frac{\sum_{i=1}^{n} h_{s i}}{\sum_{i=1}^{n} \frac{h_{s i}}{k_{i}}}
$$

Figure 5 shows us a comparison of the measured settlement, Fei et al. (2009)'s numerical result and that of the present method. Generally, the results have a reasonable agreement with each other. During construction, all the results are close and the development trends of settlement are quite similar both for pile settlement and maximum settlement. Moreover, the present method has a more conservative maximum settlement result. In post-construction, the present method has a slightly overestimated result than the other two but a closer developing trend with the measured one. The calculated final maximum settlement is $110.5 \mathrm{~mm}$ close to $104 \mathrm{~mm}$ predicted by Fei et al. (2009) using Tan's hyperbolical model. It can be seen that the present model gives a satisfactory prediction for the settlement development of the reinforced system.

time / d

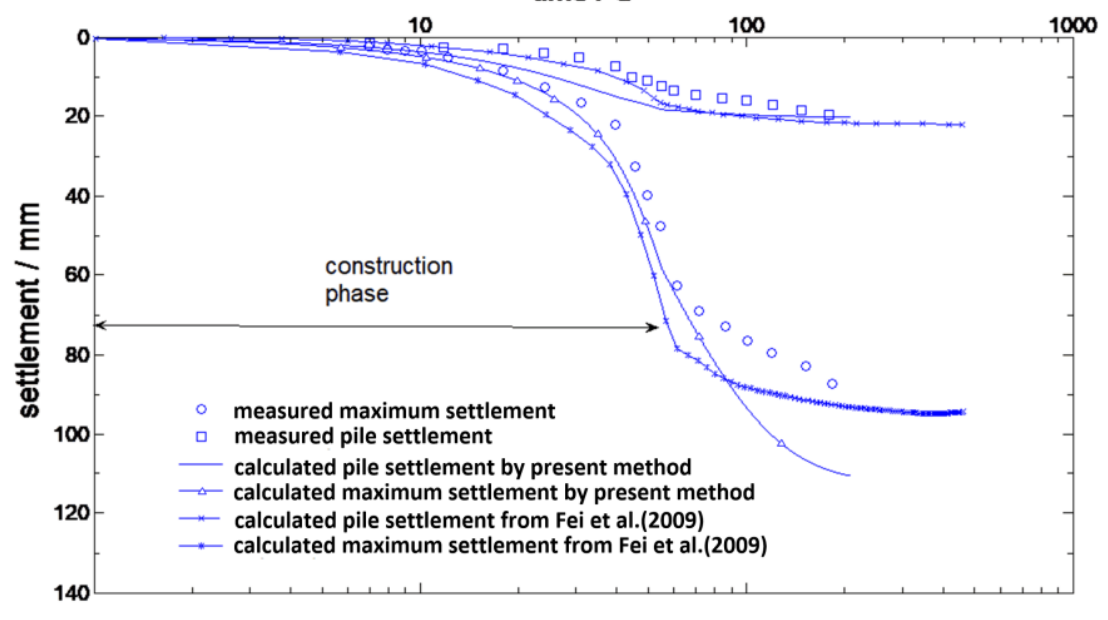

Figure 5 The development of pile settlement and maximum settlement with time 


\section{Parameter Study}

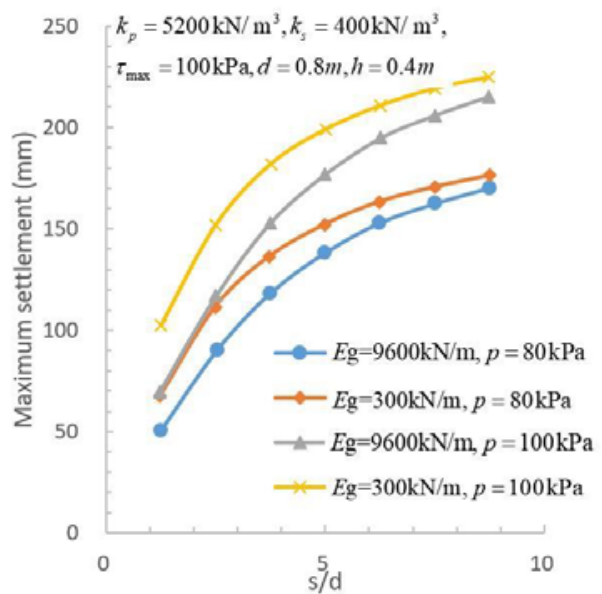

Figure 6 The maximum settlement for different load magnitudes and geosynthetics stiffnesses

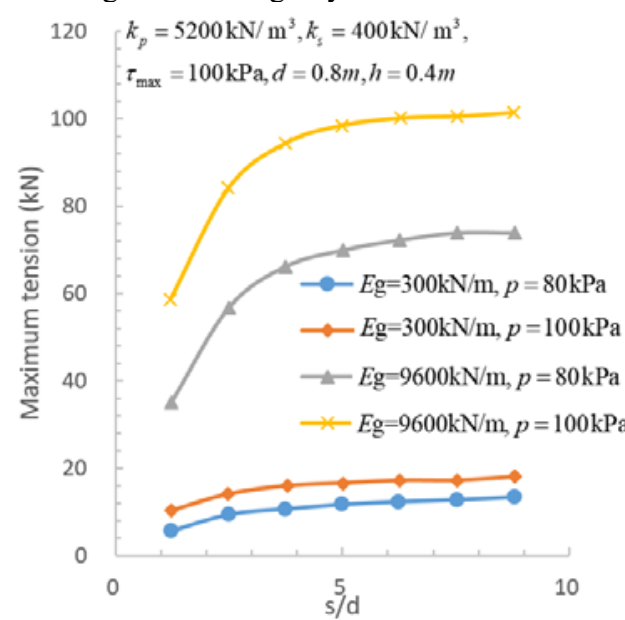

Figure 7 The maximum tension for different load magnitudes and geosynthetics stiffnesses

Fig. 6 and Fig. 7 shows the maximum settlement changing with pile-to-pitch ratio $\mathrm{s} / \mathrm{d}$ for different load densities and geosynthetics stiffnesses. With a certain load, the maximum settlement and maximum tension increase as ratio s/d increases and approach to the settlement of unreinforced foundation. The effect of increasing stiffness on deformation reducing weakens with the increase of ratio $\mathrm{s} / \mathrm{d}$. The load intensity has a significant influence on the tension. It shows up in Fig. 6 that two curves with different geosynthetics stiffnesses under the same load tensity tend to come close to each other at both ends and form a leaf shape. It can be expanded by the fact that when ratio s/d approach to unity, the adjacent piles join together so that the geosynthetics stiffness would have no influence on the maximum settlement. Similarly, when ratio s/d approaches to a big enough number, the geosynthetics stiffnesses would have no influence on the maximum settlement too. As shown in Fig.8, when ratio s/d increases from 3 to 4 under $p=$ $80 \mathrm{kPa}$, the gap of two curves increases form $17.1 \mathrm{~mm}$ to $21.1 \mathrm{~mm}$ as a peak and then decreases. Thus, we can define a critical ratio s/d under which the increase of geosynthetics stiffness can give the most benefit for deformation controlling. The critical ratio $\mathrm{s} / \mathrm{d}$ seems to be only related to the property of the cushion. For the condition as shown in fig. 6 and fig.8, this critical ratio $\mathrm{s} / \mathrm{d}$ is equal to 4 .

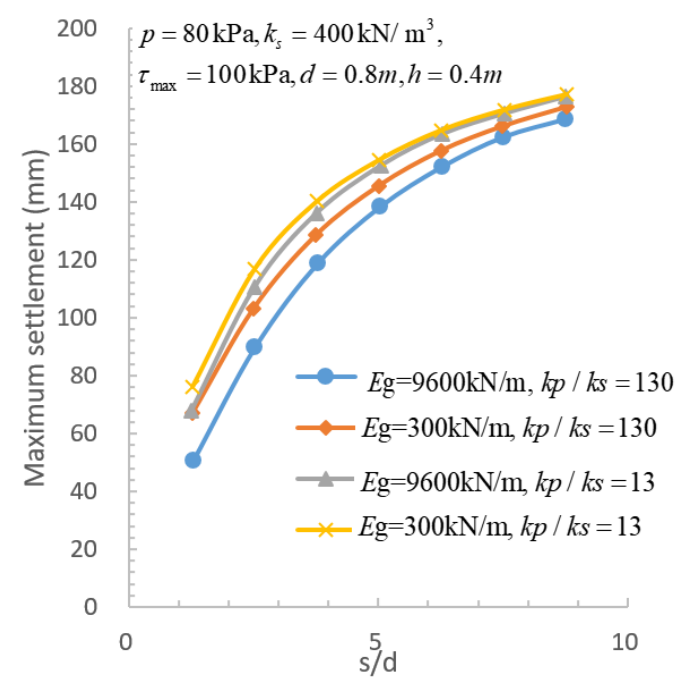

Figure 8 the maximum settlement for different $k_{p} / k_{s}$ and geosynthetics stiffnesses

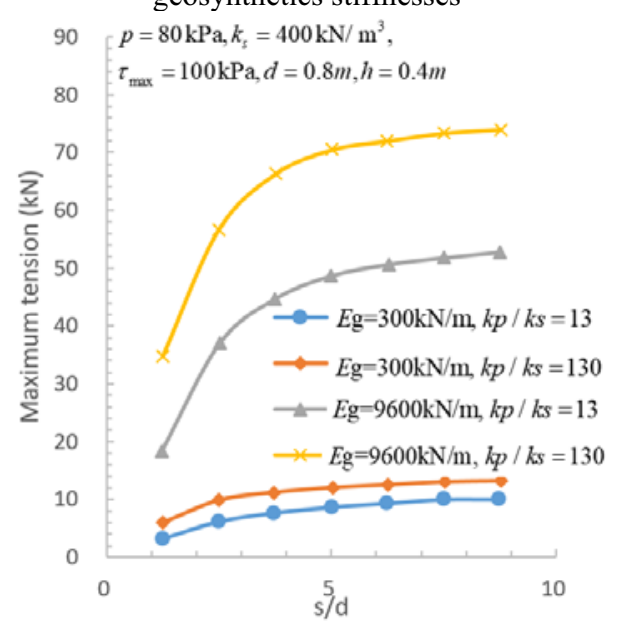

Figure 9 the maximum tension for different $k_{p} / k_{s}$ and geosynthetics stiffnesses

Fig. 8 and fig.9 shows the curves of maximum settlement and tension varying with $\mathrm{s} / \mathrm{d}$ for different ratios $k_{p} / k_{s}$ and geosynthetics stiffnesses. The effect of $k_{p} / k_{s}$ is similar with that of load tensity. The maximum tension increases as $k_{p} / k_{s}$ increases; the maximum settlement decreases as $k_{p} / k_{s}$ increases.

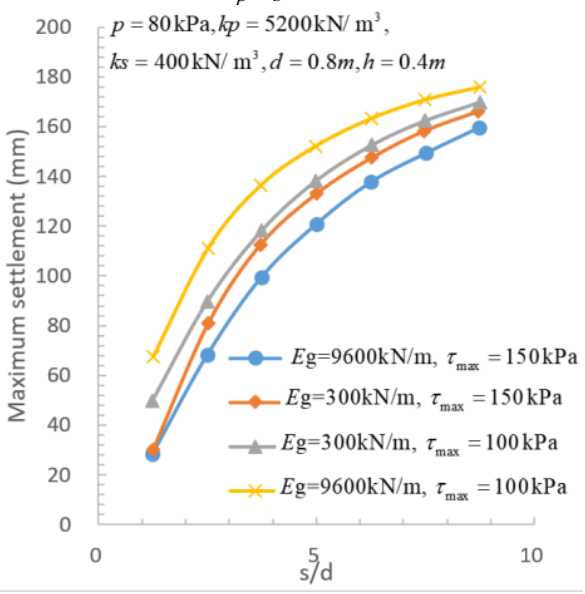

Figure 10 the maximum settlement for different ultimate strengths of the cushion and different geosynthetics stiffnesses 


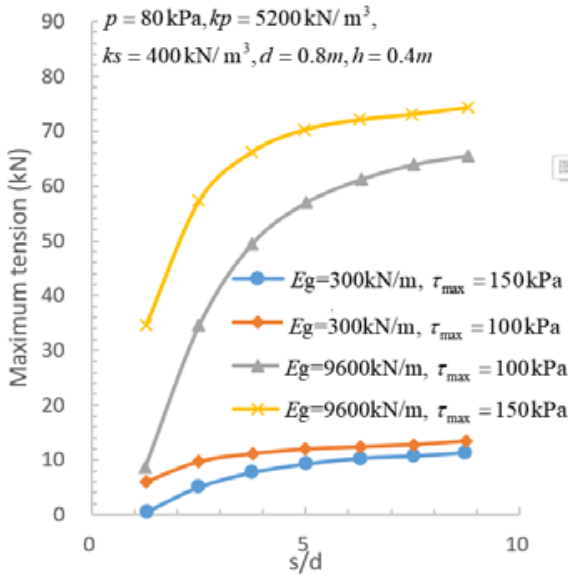

Figure 11 the maximum tension for different ultimate strengths of the cushion and geosynthetics stiffnesses

Fig.10 and fig.11 shows the curves of maximum settlement and tension varying with $s / d$ for different ultimate strengths of the cushion and geosynthetics stiffnesses. The effect of ultimate strength of the cushion is quite similar with that of load tensity. The maximum tension increases as ultimate strength of the cushion increases; the maximum settlement decreases as ultimate strength of the cushion increases.

\section{Conclusion}

A simplified planar model with a new consolidation analysis was established to analyze the behavior of the geosynthetics reinforced composite foundation. The feasibility of the model was demonstrated by a case study. A parameter study for several influential factors was executed and a critical pile-to-pitch ratio s/d was defined that makes the increase of geosynthetics layer stiffness the most conducive to deformation control. And the critical s/d seems to only depend on the property of the cushion.

In the beginning of consolidation, the surcharge load is mainly undertaken by excess pore pressure. With the consolidation of subsoil, due to the stiffness diversity between the subsoil and pile, differential settlement happens. Sequentially, the shearing of the cushion and the deformation of geosynthetics layer happen to transmit the surcharge load to the pile-liked inclusions. In return, the increase of the load applied on the pile lead to larger pile settlement to alleviate the differential settlement. The load distribution is dynamically adjusted until the finish of consolidation.

\section{Acknowledgements}

The study was supported by the Project of Zhejiang Provincial Communication Department (No.2019058) and the Scientific research project of Zhejiang Highway Administration Bureau (No.2018H19), which is greatly appreciated.

\section{Reference}

1. C.J.F.P. Jones, C.R. Lawson, D.J. Ayres.
Geosynthetic reinforced piled embankments. In: Hoedt, Den (Ed.), Geosynthetics, Geomembranes and Related Products. Balkema, Rotterdam, pp. 155-160 (1990).

2. B.K. Low, S.K. Tang, V. Choa. Arching in piled embankments. Journal of Geotechnical Engineering 120 (11), 1917-1938 (1994).

3. D. Russell, N. Pierpoint. An assessment of design methods for piled embankments. Ground Engineering, 30 (10), 39-44 (1997).

4. M.R. Madhav, H.B. Poorooshasb. A new model for geosynthetic-reinforced soil. Comput. Geotech.,6(4), 277-290 (1988).

5. S.K. Shukla, S. Chandra. The effect of prestressing on the settlement characteristics of geosynthetic-reinforced soil. Geotext.Geomembr.,13(8), 531-543 (1994).

6. S.K. Shukla, S. Chandra. Modeling of geosynthetic reinforced engineered granular fill on soft soil. Geosynthet. Int.,2(3), 603-617 (1995).

7. K. Deb, S. Chandra, P. K. Basudhar. Settlement response of a multilayer geosynthetic-reinforced granular fill-soft soil system. Geosynthet. Int.,12(6), 288-298, (2005).

8. K. Deb, P. K. Basudhar, S. Chandra. Generalized model for geosynthetic-reinforced granular fill-soft soil with stone columns. Int. Journal of Geomechanics., 7 (4), 266-276 (2007).

9. J.H. Yin. Modelling Geosynthetic-Reinforced Granular Fills Over Soft Soil. Geosynthet. Int., 4 (2), 165-185 (1997).

10. R. L. Kondner. Hyperbolic stress-strain response: cohesive soils. J. Soil Mech. and Found. Div.,89(1), 115-143 (1963).

11. C.C. Hird, I.C. Pyrah, D. Russell. Finite element modeling of vertical drains beneath embankments on soft ground. Geotechnique, 423, 499-511 (1992).

12. L. Zhang, M.H. Zhao, Y.X. Hu, H. Zhao, B.C. Chen. Semi-analytical solutions for geosynthetic-reinforced and pile-supported embankment. Computers and Geotechnics, 44 (2012) 167-175 (2012).

13. G.L Zhou. The influence of the variability among piles on the stresses in foundation beams and its calculation. J. Hunan Univ., 12(3):37-51 (1985). 